\title{
Study on Thickness Thinning Ratio of the Forming Parts in Single Point Incremental Forming Process
}

\author{
Mingshun Yang $\mathbb{D}^{1},{ }^{1}$ Zimeng Yao $\mathbb{D},{ }^{1}$ Yan Li $\left(\mathbb{D},{ }^{1}\right.$ Pengyang Li, ${ }^{1}$ Fengkui Cui, ${ }^{2}$ and Lang Bai $\mathbb{I D}^{1}$ \\ ${ }^{1}$ Faculty of Mechanical and Precision Instrument Engineering, Xi'an University of Technology, Xi'an 710048, China \\ ${ }^{2}$ School of Mechatronics Engineering, Henan University of Science and Technology, Luoyang, China \\ Correspondence should be addressed to Zimeng Yao; 15829585702@163.com
}

Received 9 January 2018; Revised 24 May 2018; Accepted 30 May 2018; Published 24 June 2018

Academic Editor: Laszlo Toth

Copyright (c) 2018 Mingshun Yang et al. This is an open access article distributed under the Creative Commons Attribution License, which permits unrestricted use, distribution, and reproduction in any medium, provided the original work is properly cited.

An excessive thickness-reducing ratio of the deformation zone in single point incremental forming of the metal sheet process has an important influence on the forming limit. Prediction of the deformation zone thickness is an important approach to control the thinning ratio. Taking the 1060 aluminum as the research object, the principle of thickness deformation in the single point incremental forming process was analyzed; the finite element model was established using ABAQUS. A formula with high accuracy to predict the deformation zone thickness was fitted with the simulation results, and the influences of process parameters, such as tool diameter, step down, feeding speed, sheet thickness, and forming angle, on thinning ratio were analyzed. The accuracy of the finite element simulation was verified by experiment. A method to control the thinning rate by changing the forming trajectory was proposed. The results showed that the obtained value by using the fitted formula is closer to the experimental results than that obtained by the sine theorem. The thinning rate of the deformation zone increases with the increase of tool diameter, forming angle, and sheet thickness and decreases with the increase of step down, while the feeding speed had no significant effect on the thinning ratio. The most important factor of the thinning ratio is the forming angle, and the thinning ratio can be effectively reduced by using the forming trajectory with a uniformly distributed pressing point.

\section{Introduction}

Single point incremental forming (SPIF) is a new type of sheet metal-forming technology integrating numerical control (NC) technology, computer technology, and plasticforming technology [1]. In the forming process, according to the shape of the target part, CAM software is used to generate a toolpath with a series of high-profile NC codes, and the tool subsequently follows the toolpath generated and deforms the sheet in small increments, accumulating plastic deformation between the tool and material that can result in obtaining the target shape [2]. Better flexibility, lower cost, high degree of automation, and enhanced formability are special features of this process in the customized and small batch production of metal sheet parts, especially in artificial, medical appliance, aerospace, and household products $[3,4]$.

The forming quality, including the excessive thinning rate of wall thickness, is still one of the greatest challenges for the development of single point incremental forming [5-7]. The thickness thinning ratio is directly related to the formability of the forming parts; thus, the study of the thickness law of forming parts is of great significance [8]. There are many studies from researchers all over the world on the thickness rules of forming parts. McAnulty et al. [9] analyzed the experimental results from 35 papers that reported the study of the influence of process parameters (tool diameter, tool shape, step down, feed rate, rotation direction, and spindle speed) on the formability in SPIF. Malhotra et al. [10] used a fracture model and finite element analyses to predict the fracture in SPIF of the cone and the funnel parts; the forming forces, fracture depths, and thinning from finite element analyses were used to validate predictions, and the results showed that the local nature of deformation was a primary factor for the increased formability in SPIF. Hussain et al. [11] obtained the final thickness of the forming parts with varying wall angle by the sine law; on this basis, 
the maximum wall angle was obtained from four conical frustums of varying wall angle. Jackson and Allwood [12] analyzed the wall thickness using the deformation mechanism of SPIF. Kim and Park [13] analyzed the influence of processing parameters on the wall thickness. Bouffioux et al. [14] simulated the forming process and provided better forecasting of the wall thickness. Silva et al. [15] investigated the failure mechanisms in SPIF with different tool radii and the evolution of the wall thickness of truncated pyramids with five different tool radii; the results showed that a critical threshold exists for the ratio between the sheet thickness and the tool radius that distinguishes between fracture with and without previous necking. Young and Jeswiet [16] found that the thickness of the deforming region only depends on the forming angle by theoretical analysis and used the cosine theorem to predict the sheet thickness value. Hirt et al. [17] verified the cosine theorem through experiments and finite element simulations. Al-Ghamdi and Hussain [18] found that the ratio of the tool radius to the sheet thickness could control the formability in SPIF; the ratio was a threshold value, and the formability was noticed to increase with decrease in the tool radius above the threshold value and decrease with the reduction in tool radius below the threshold value. Martins et al. [19] proposed that the cosine theorem is suitable for deformation thickness prediction and that only shear deformation occurred in the sheet-forming process. Zhou [20] studied the influence of the forming angle on the thickness value of the deformation area and analyzed the thickness of deformation region in a straight wall. Xiao and Gao [21] adopted the method of numerical simulation and experiment to study the critical forming angle of uniform thickness in the single point incremental forming of a conical part process. Li [22] found that the minimum sheet thickness is closely related to the tool diameter and that work hardening can lead to sheet material strength enhanced significantly. Yu and Gao [23] proposed a theoretical calculation formula for the minimum wall thickness and reduced the sheet thinning successfully by multistep forming. Cao and Gao [24] found a method to produce parts with equal wall thickness by means of increasing processing variables after analyzing the relationships among feed, plate material thickness, forming angle, and maximum stable area. Wei and Gao [25] developed thickness prediction software based on the law of sines that could accurately predict the part's thickness. Zhao and Zhan [26] obtained thinning distribution and sheet distortion pattern after studying the metal flawing law in the forming process.

The current study on thickness thinning is mainly based on the shear deformation that occurs under the action of the forming tool on sheet material, for which the sine law is not adequate in predicting and controlling the wall thickness. In this paper, the single point incremental forming process of a 1060 aluminum sheet is simulated with finite element simulation software ABAQUS to study the influences of different process parameters, including tool diameter, step down, feeding speed, sheet thickness, and forming angle, on the wall thinning. The experimental results obtained are fitted by MATLAB to generate an empirical formula that could better predict the wall thickness, and the formula is verified by experiments on HASS milling machine; the
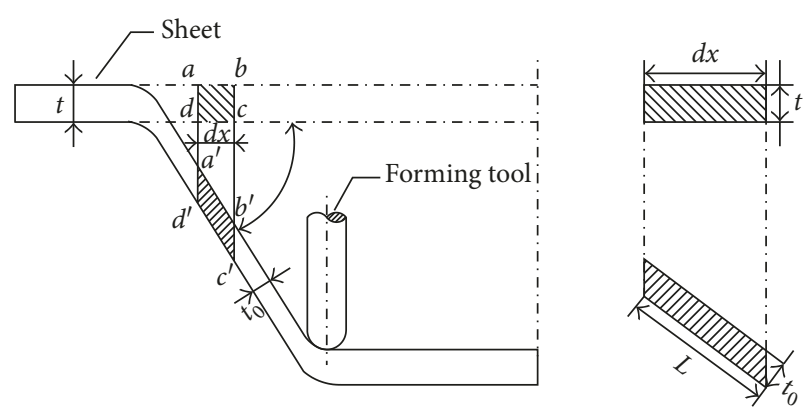

FIGURE 1: Illustration of the shear deformation in the SPIF process. $\alpha$ is the forming angle, $t$ is the initial sheet thickness, $t_{0}$ is the thickness of deformation, $a b c d$ with length of $d x$ is the unit to be deformed, and $a^{\prime} b^{\prime} c^{\prime} d^{\prime}$ is the deformed unit.

formula predicting the wall thickness in the forming area and method to control the thinning rate are obtained.

\section{Theoretical Background}

Single point incremental forming process is a nonlinear large displacement process. The plastic deformation of metal material results in the continuous squeezing of the material as the tool is moved. Because the axial force is greater than the radial and tangential forces in the forming process, it is usually assumed that shear deformation occurs only in the axial direction, as shown in Figure 1.

According to the constant volume principle in plastic deformation, the following formula can be obtained:

$$
\begin{aligned}
t \cdot d x & =t_{0} \cdot L, \\
d x & =L \cdot \cos \alpha,
\end{aligned}
$$

From the above, $t_{0}$ can be calculated as $t_{0}=t \cos \alpha$.

The wall thinning rate is an important indicator of formability that can reflect the thickness variation law and changing scope of the metal sheet. When the wall thinning rate exceeds a certain range, the part will have lower strength, thereby greatly affecting the precision of the formed part. The wall thinning rate can be defined as follows:

$$
\varphi=\frac{t-t_{0}}{t} \times 100 \% \text {. }
$$

In the forming process, both radial movement and tangential movement occur while the tool moves along the axial direction, and the sheet will generate radial deformation and tangential deformation via the squeezing force and friction force of the forming tool. Although tangential deformation and radial deformation are smaller than the axial deformation, they still have effects on the wall thickness distribution. Therefore, the thinning rate obtained from formulas (1) and (2) is not accurate enough, and the thinning rate of the forming part is in relation to not only the initial thickness and forming angle, but also the tool forming diameter, step down, and feeding speed. Based on formula (1), the systematically comprehensive wall thickness calculation formula is given by

$$
t_{0}=a \cdot D+b \cdot Z+c \cdot F+d \cdot \alpha+e \cdot t+f,
$$

where $a, b, c, d, e$, and $f$ are undetermined coefficients, $D$ is the tool diameter, $Z$ is the step down, and $F$ is the feed speed. 


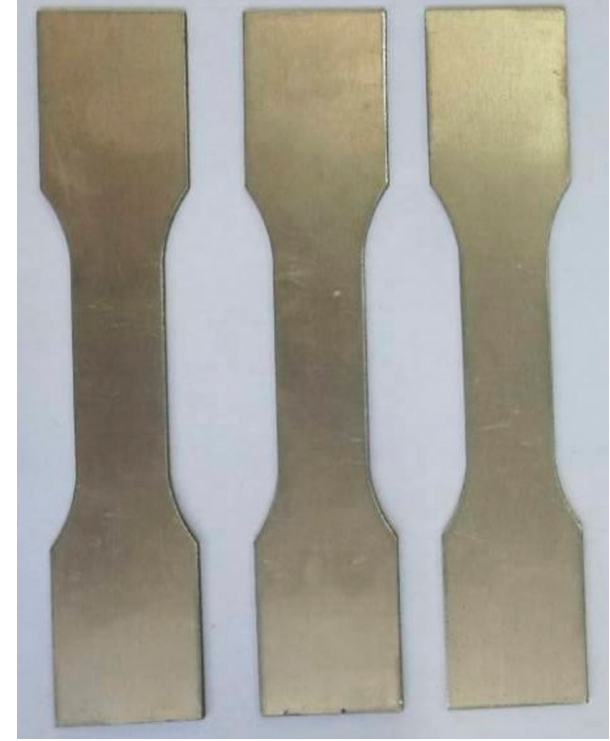

Figure 2: Tension test specimen.

In this paper, the relationship between the wall thinning rate and the processing parameters are established by simulation results and the undetermined coefficients are obtained; the formula and the simulation results are verified experimentally.

\section{FEM Simulation}

3.1. Simulation Model. The commercial finite element software ABAQUS can solve the problems of nonlinear materials and geometrically nonlinear problems, as well as accurately simulating the contact process with long contact time and large plastic deformation. ABAQUS is used as the finite element simulation software combined with the characteristics of SPIF. The sheet material is 1060 aluminum; the specimens are shown in Figure 2. The tensile test is conducted on the HT2402 tensile test machine, as shown in Figure 3; the loading speed is $1.5 \mathrm{~mm} / \mathrm{min}$ and the temperature is room temperature $\left(20^{\circ} \mathrm{C}\right)$, with each specimen being subjected to three repeated tests, and the average value is taken as the final tensile test result of the specimen. The material properties and the stress-strain properties are shown in Tables 1 and 2, respectively. In performing the simulation, because the experiment device of SPIF is a relatively complex experimental system, to reduce the difficulty of modeling and shorten the time of simulation, some simplifications are used under the unchanged relative motion relationship. The model consists of a spherical forming tool, a fixture, and a metal sheet; the fixture is simplified as two rings of the same size. The model can satisfy the relative motion relationship in the forming process by applying the boundary conditions. Forming tools and fixtures are considered as rigid bodies in the model; a rigid body does not participate in the calculation of stress and strain, thereby, saving CPU computing resources and reducing the computation time. The sheet size is $140 \mathrm{~mm} \times 140 \mathrm{~mm}$; the outer radius of the fixture is $70 \mathrm{~mm}$, the inner radius of the fixture is $55 \mathrm{~mm}$, and the upper radius of the forming part is $45 \mathrm{~mm}$.

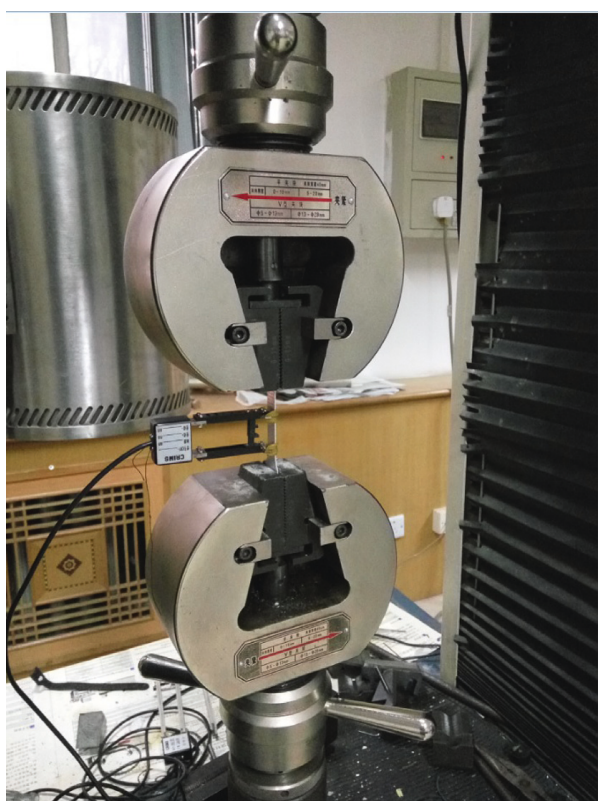

Figure 3: Tension test machine.

TABLE 1: Materials properties of 1060 aluminum.

\begin{tabular}{ccccc}
\hline Material & $\begin{array}{c}\text { Density } \\
\rho\left(\mathrm{g} / \mathrm{mm}^{3}\right)\end{array}$ & $\begin{array}{c}\text { Elastic modulus } \\
(\mathrm{GPa})\end{array}$ & $\begin{array}{c}\text { Poisson's } \\
\text { ratio }\end{array}$ & $\begin{array}{c}\text { Yield strength } \\
(\mathrm{Mpa})\end{array}$ \\
\hline Al 1060 & 2.71 & 70 & 0.3 & 30 \\
\hline
\end{tabular}

TABLE 2: Stress-strain properties of 1060 aluminum material.

\begin{tabular}{lccccccc}
\hline $\begin{array}{l}\text { Stress } \\
(\mathrm{MPa})\end{array}$ & 20 & 44 & 64 & 77 & 87 & 91 & 98 \\
\hline Strain & 0.002 & 0.0169 & 0.0507 & 0.0845 & 0.1183 & 0.1352 & 0.169 \\
\hline
\end{tabular}

The process parameters depend on the experimental conditions. SPIF is a complex plastic-forming process and a dynamic contact problem that requires high efficiency and a stable dynamic property algorithm. Taking A1 in Table 3 as an example, the simulation time is $121381 \mathrm{~s}$, and the numerical simulation is conducted on a computer equipped with an Intel Core i7-6700 (3.4 GHz) and $32 \mathrm{~GB}$ memory.

Unit selection and grid division should follow accurate and efficient principles; thus, the S4R shell element was selected to simulate the forming process, and the mesh size is $1 \mathrm{~mm} \times 1 \mathrm{~mm}$. The forming tool and fixture do not need to be divided because they are rigid bodies. The surface-surface contact model was used, the dynamic explicit algorithm was selected, and a penalty function was employed. Coulomb friction was chosen as the friction type because the tangential force is smaller than the axial and radial forces.

Because the trajectory of forming tool is complex in the forming process, it is necessary to simulate the trajectory by periodic amplitude curves when simulation-forming cone parts. The forming tool will follow $X=A_{1} \cos \left(2 \pi t_{n}\right)$ in the $X$ direction and follow $Y=B_{1} \sin \left(2 \pi t_{n}\right)$ in the $Y$ direction, where $A_{1}$ and $B_{1}$ are the radius and $t_{n}$ is the analysis step time; the motions along the $X$ and $Y$ directions can be synthesized 
TABLE 3: Experimental parameter.

\begin{tabular}{lccccc}
\hline Number & Tool diameter $(\mathrm{mm})$ & Step down $(\mathrm{mm})$ & Feed speed $(\mathrm{mm} / \mathrm{min})$ & Forming angle $\left(^{\circ}\right)$ & Sheet metal thickness $(\mathrm{mm})$ \\
\hline A1 & 6 & 1 & 200 & 45 & 0.8 \\
A2 & 10 & 1 & 200 & 45 & 0.8 \\
A3 & 14 & 1 & 200 & 45 & 0.8 \\
B1 & 10 & 0.6 & 200 & 45 & 0.8 \\
B2 & 10 & 0.8 & 200 & 45 & 0.8 \\
B3 & 10 & 1 & 200 & 45 & 0.8 \\
C1 & 10 & 1 & 100 & 45 & 0.8 \\
C2 & 10 & 1 & 200 & 45 & 0.8 \\
C3 & 10 & 1 & 300 & 45 & 0.8 \\
D1 & 10 & 1 & 200 & 53 & 0.8 \\
D2 & 10 & 1 & 200 & 45 & 0.8 \\
D3 & 10 & 1 & 200 & 45 & 0.8 \\
E1 & 10 & 1 & 200 & 45 & 0.8 \\
E2 & 10 & 1 & 200 & & 1 \\
E3 & 10 & 1 & 200 & & \\
\hline
\end{tabular}

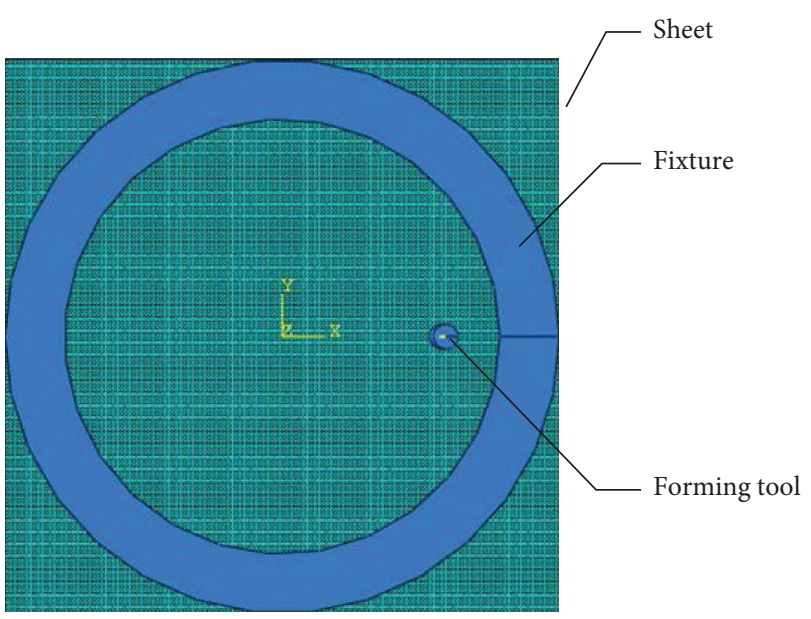

FIGURE 4: Finite element model.

to generate the trajectory for forming tool. The FE model and the target shape are shown in Figures 4 and 5, respectively.

3.2. Simulation Scheme. There are many parameters affecting the thickness thinning ratio in the single point incremental forming process. The simulation scheme is designed to include five forming parameters (forming tool diameter, step down, feed speed, sheet thickness, and forming angle), as shown in Table 3.

3.3. Simulation Results and Analysis. By using the view section function, the part is symmetrically cut along the $X-Z$ section; "STH" is selected, which means sheet thickness; the sheet thickness is output to display the wall thickness, and the inquiry function is used to obtain the thickness values of five cells in the stable zone, respectively, located at depths of $10 \mathrm{~mm}, 13 \mathrm{~mm}, 15 \mathrm{~mm}, 17 \mathrm{~mm}$, and $20 \mathrm{~mm}$. The simulation results of the thickness distribution are shown in Figure 6, and the thickness values of different parameters are shown in Table 4.

Using multilinear regression to fit the above data using MATLAB, the undetermined coefficients of (3) could be

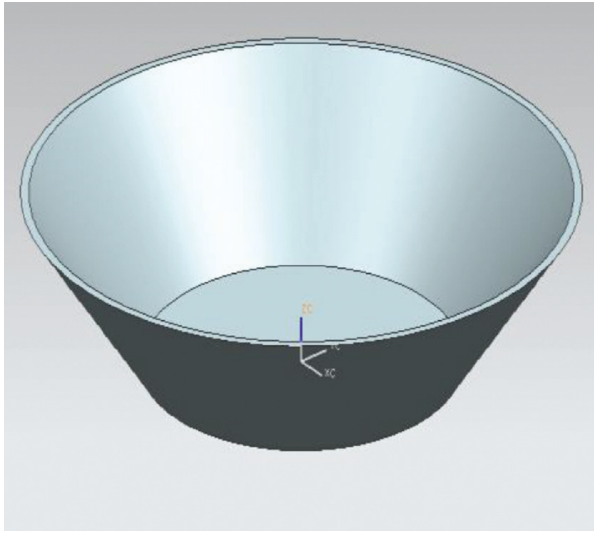

FIgURE 5: Target shape.

obtained. Thus, the wall thickness can be calculated as follows:

$$
\begin{aligned}
t_{0}= & 0.59-0.0016 \cdot D+0.0065 \cdot Z \\
& +0 \cdot F-0.0127 \alpha+0.6755 \cdot t
\end{aligned}
$$

The initial thickness $t$ in Table 3 and the average thickness $t_{0}$ of the forming area in Table 4 were substituted in (2). The relationship between the thickness thinning ratio and the processing parameters obtained is shown in Figure 7.

The wall thinning rate clearly increases from $31.17 \%$ to $32.85 \%$ when the tool diameter changes from $6 \mathrm{~mm}$ to $14 \mathrm{~mm}$ (A1 to A3). The wall thinning rate decreases from $31.7 \%$ to $31.32 \%$ when the step down changes from $0.6 \mathrm{~mm}$ to $1.0 \mathrm{~mm}$ (B1 to $\mathrm{B} 3$ ), but the variation is not obvious. Based on the data of experiment nos. $\mathrm{C} 1 \sim \mathrm{C} 3$, the wall thinning rate remains approximately $31.30 \%$ with the feed speed changing; that is, the feed speed has little effect on the thinning rate. According to the data of experiment nos. D1 D3, the wall thinning rate increases from $31.32 \%$ to $55.91 \%$ when the forming angle changes from $45^{\circ}$ to $60^{\circ}$; thus, the forming angle has a great influence on the thinning rate. From the data of experiment nos. E1 E3, the wall thinning rate increases from $31.03 \%$ to $31.60 \%$ when the sheet thickness 


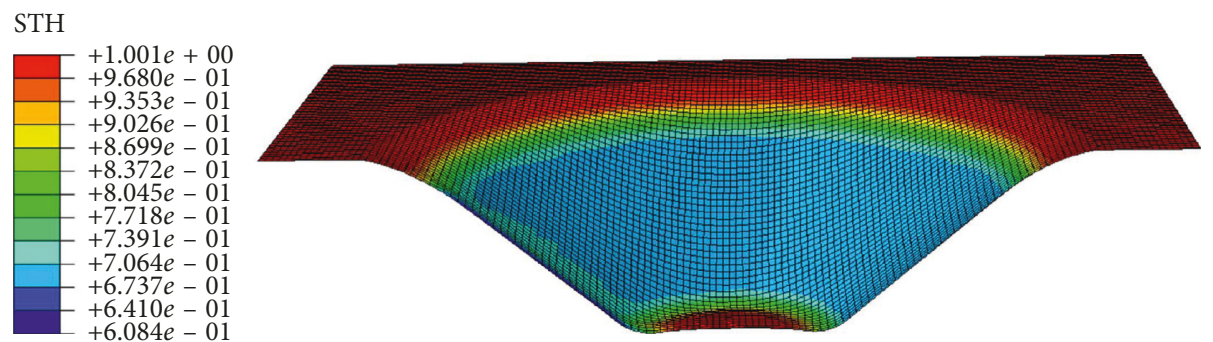

FIGURE 6: Simulation results.

TABLE 4: Thickness value.

\begin{tabular}{|c|c|c|c|c|c|c|}
\hline Thickness number & $10 \mathrm{~mm}$ & $13 \mathrm{~mm}$ & $15 \mathrm{~mm}$ & $17 \mathrm{~mm}$ & $20 \mathrm{~mm}$ & Average $(\mathrm{mm})$ \\
\hline A1 & 0.5540 & 0.5447 & 0.5529 & 0.5554 & 0.5434 & 0.5501 \\
\hline A2 & 0.5491 & 0.5390 & 0.5414 & 0.5399 & 0.5433 & 0.5425 \\
\hline A3 & 0.5396 & 0.5350 & 0.5241 & 0.5450 & 0.5424 & 0.5372 \\
\hline B1 & 0.5448 & 0.5409 & 0.5487 & 0.5508 & 0.5438 & 0.5458 \\
\hline B2 & 0.5506 & 0.5389 & 0.5485 & 0.5517 & 0.5550 & 0.5489 \\
\hline B3 & 0.5471 & 0.5530 & 0.5448 & 0.5536 & 0.5487 & 0.5494 \\
\hline $\mathrm{C} 1$ & 0.5647 & 0.5388 & 0.5515 & 0.5452 & 0.5482 & 0.5497 \\
\hline $\mathrm{C} 2$ & 0.5471 & 0.5530 & 0.5448 & 0.5536 & 0.5487 & 0.5494 \\
\hline $\mathrm{C} 3$ & 0.5494 & 0.5471 & 0.5518 & 0.5538 & 0.5469 & 0.5498 \\
\hline D1 & 0.5471 & 0.5530 & 0.5448 & 0.5536 & 0.5487 & 0.5494 \\
\hline D2 & 0.4491 & 0.4420 & 0.4628 & 0.4612 & 0.4562 & 0.4543 \\
\hline D3 & 0.3637 & 0.3365 & 0.3411 & 0.3639 & 0.3583 & 0.3527 \\
\hline E1 & 0.4193 & 0.4061 & 0.4128 & 0.4175 & 0.4134 & 0.4138 \\
\hline E2 & 0.5471 & 0.5530 & 0.5448 & 0.5536 & 0.5487 & 0.5494 \\
\hline E3 & 0.6905 & 0.6804 & 0.6828 & 0.6813 & 0.6847 & 0.6840 \\
\hline
\end{tabular}

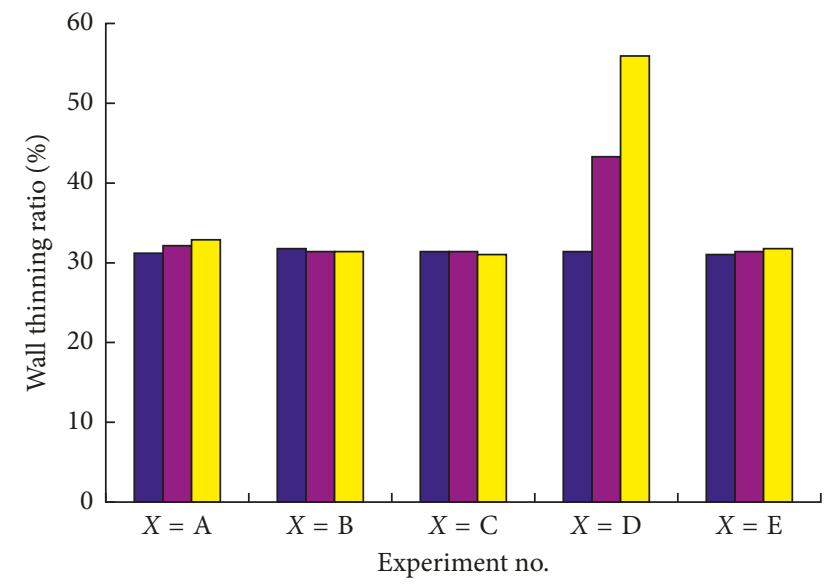

$\square 1$
$\square \quad X 2$
$\square \quad X 3$

Figure 7: Relationship between thickness thinning ratio and process parameters.

increases from $0.6 \mathrm{~mm}$ to $1.0 \mathrm{~mm}$, that is, the variation is not obvious.

\section{Experimental Results}

As shown in Figure 8, the HASS high-speed NC milling machine was used. The size of fixture is the same as that in the simulation model, and the experiment parameters are

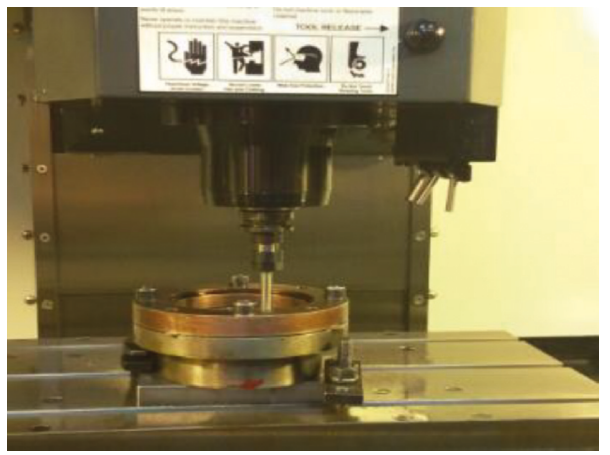

FIGURE 8: SPIF experiment unit.

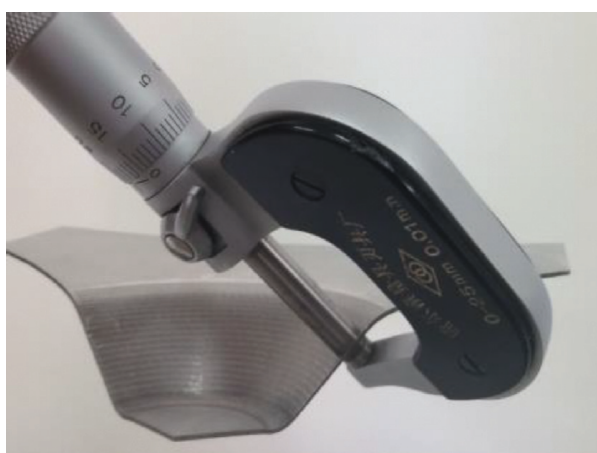

FIgURE 9: The measuring method. 
TABLE 5: Comparison between the theoretical and experimental results of the average thickness value.

\begin{tabular}{lcccccccccccccccccc}
\hline & \multicolumn{3}{c}{ Tool diameter $(\mathrm{mm})$} & \multicolumn{3}{c}{ Step down $(\mathrm{mm})$} & \multicolumn{3}{c}{$\begin{array}{c}\text { Feed speed } \\
(\mathrm{mm} / \mathrm{min})\end{array}$} & \multicolumn{4}{c}{ Forming angle $\left(^{\circ}\right)$} & $\begin{array}{c}\text { Feed speed } \\
(\mathrm{mm} / \mathrm{min})\end{array}$ \\
& 6 & 10 & 14 & 0.6 & 0.8 & 1.0 & 100 & 200 & 300 & 45 & 53 & 60 & 0.62 & 0.81 & 1.08 \\
\hline$t_{\text {experiment }}$ & 0.630 & 0.616 & 0.616 & 0.607 & 0.622 & 0.616 & 0.606 & 0.616 & 0.603 & 0.616 & 0.492 & 0.381 & 0.458 & 0.616 & 0.845 \\
$t_{\text {fitting }}$ & 0.625 & 0.612 & 0.615 & 0.608 & 0.610 & 0.612 & 0.603 & 0.612 & 0.584 & 0.612 & 0.475 & 0.421 & 0.450 & 0.612 & 0.802 \\
$t_{\text {initial }}$ & 0.638 & 0.631 & 0.631 & 0.630 & 0.630 & 0.631 & 0.622 & 0.631 & 0.587 & 0.631 & 0.506 & 0.446 & 0.453 & 0.631 & 0.834 \\
$p_{\text {fitting }}$ & 0.79 & 0.65 & 0.16 & 0.16 & 1.92 & 0.65 & 0.49 & 0.65 & 3.15 & 0.65 & 3.46 & 10.50 & 1.70 & 0.65 & 5.09 \\
$p_{\text {fitting }}$ & 1.27 & 2.43 & 2.43 & 3.79 & 1.29 & 2.44 & 2.64 & 2.44 & 2.65 & 2.44 & 2.85 & 17.06 & 5.59 & 2.44 & 1.30 \\
\hline
\end{tabular}

the same as those in Table 3. The measured sheet thickness values are shown in Figure 9; the formed part was cut along the wall thickness direction with the help of wire-electrode cutting, and then the thickness value was obtained using a micrometer. To minimize error, an average of five readings was calculated to represent the thickness for each forming part. The thickness values of the formed part at depths of $10 \mathrm{~mm}, 13 \mathrm{~mm}, 15 \mathrm{~mm}, 17 \mathrm{~mm}$, and $20 \mathrm{~mm}$ were measured.

The theoretical wall average thickness value $t_{\text {initial }}(\mathrm{mm})$ in the forming area can be calculated using (1), and the error value of the experiment wall average thickness value $t_{\text {experiment }}$ $(\mathrm{mm})$ is $p_{\text {initial }}(\%)$. The fitting wall average thickness value $t_{\text {fitting }}$ in the forming area can be calculated using (4), and the error value with the experiment wall average thickness value $t_{\text {experiment }}(\mathrm{mm})$ is $p_{\text {fitting }}$. The comparison results are shown in Table 5 and Figure 10.

Table 5 and Figure 10 show that the fitting formula has better accuracy than the initial formula, demonstrating that the fitting formula based on the simulation results can better predict the thickness than the cosine calculation formula. According to (2), the relationship between the thickness thinning ratio and the processing parameters obtained is shown in Figure 11.

Li et al. [8] studied the effect of SPIF on the thickness distribution through experimental investigations and found that the tool diameter and step down was nearly independent of the location of thickness; however, the thickness thinning ratio was found to increase continuously as the tool diameter grows. The same variation is clearly observed in Figure 11: the wall thinning ratio clearly increases from $30.15 \%$ to $32.11 \%$ when the tool diameter changes from $6 \mathrm{~mm}$ to $14 \mathrm{~mm}$ (A1 to A3) but no obvious change occurs in the thinning rate (decreasing from $31.87 \%$ to 31.02) with the step down changing from $0.6 \mathrm{~mm}$ to $1.0 \mathrm{~mm}$ (B1 to B3). Bagudanch et al. [27, 28] obtained the maximum temperature, forming force, formability, and surface roughness in the SPIF by using the design of experiments approach; the results showed that the feed speed has a significant influence on the maximum temperature and the forming force, whereas it has little effect on the formability. Therefore, from the data of experiment nos. C1 C3, the feed speed has little effect on the thickness thinning ratio. According to the cosine calculation formula, the forming angle has the most significant effect on the thickness; from the data of experiment nos. D1 D3, the wall thinning rate increases from $31.02 \%$ to $57.29 \%$, with the forming angle changing from $45^{\circ}$ to $60^{\circ}$. From the data of experiment nos. E1 E3, the wall thinning rate increases from $29.66 \%$ to $32 \%$, with the sheet thickness changing from $0.6 \mathrm{~mm}$ to $1.0 \mathrm{~mm}$.
Taking A1 as an example, the results of the thickness ratio obtained from the simulation and experiment are $31.17 \%$ and $30.15 \%$, showing that the results of the simulation are correct and reliable. The forming tool is assumed to be a rigid body in the simulation process, and the wastage of the sheet and tool caused by friction is not considered; a degree of deviation is found between the simulation and experiment results, but the deviation is notably small. Therefore, the simulation results can be used to guide the experiment to reduce the thinning rate.

\section{Method of Controlling the Thinning Ratio}

According to the previous analysis, the thickness thinning ratio of the deformation zone affects the strength and formability of the forming parts, and the tool diameter, the step down, the forming angle, and other processing parameters affect the thinning ratio. On this basis, the forming trajectory has a great influence on the forming process [29]; therefore, it is necessary to study the influence of the forming trajectory on the thickness thinning ratio. It is expected that the thinning rate can be controlled by controlling the forming trajectory. In previous simulations and experimental processing, the tool was found to always move along only one direction and the pressure point was found to be concentrated at the same location; thus, the material cannot flow uniformly in forming process, and the thinning ratio of the forming region will become notably large when the impresses are produced, as shown in Figure 12.

To ensure the material flows more uniformly, it is best to control the sheet thinning rate and increase the thickness of the forming region. The alternating inversion trajectory and uniformly press point trajectory are employed to simulate the forming process. A sheet with a thickness value of $1 \mathrm{~mm}$ and three different forming trajectories are used to simulate the process for the same processing parameters. The three different forming trajectories are shown in Figure 13.

The experimental forming parts and the simulation results under three forming trajectories are shown in Figures 14 and 15 , respectively; the thickness distribution is found to be the most uniform under the uniformly press point trajectory.

The simulation results and experimental results of the wall thickness for the three different forming trajectories are shown in Figure 16; the simulation results are found to be close to the experimental results. The simulation results are as follows: the average thickness is $0.6840 \mathrm{~mm}$ and the thinning rate is $31.6 \%$, for the single forming trajectory; the average thickness is $0.6920 \mathrm{~mm}$ and the thinning rate is $30.8 \%$, for the 

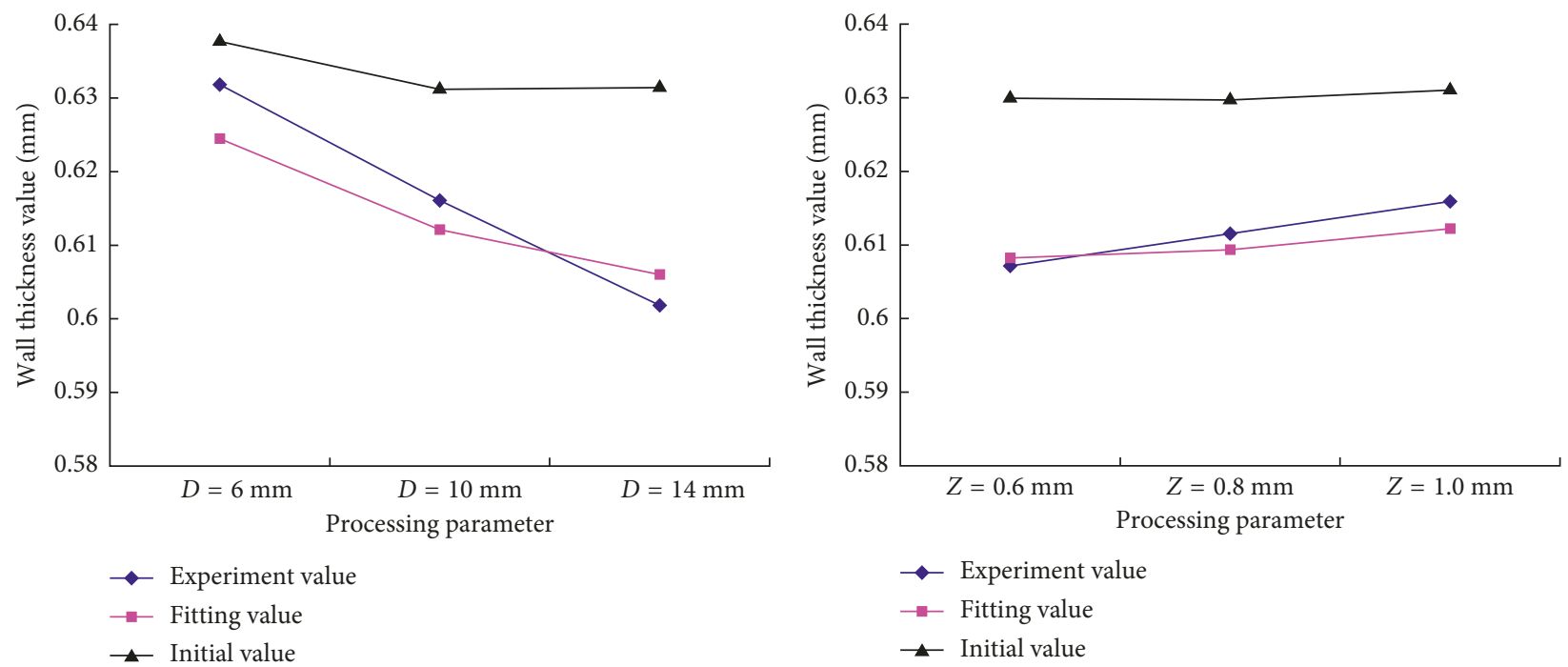

(a)

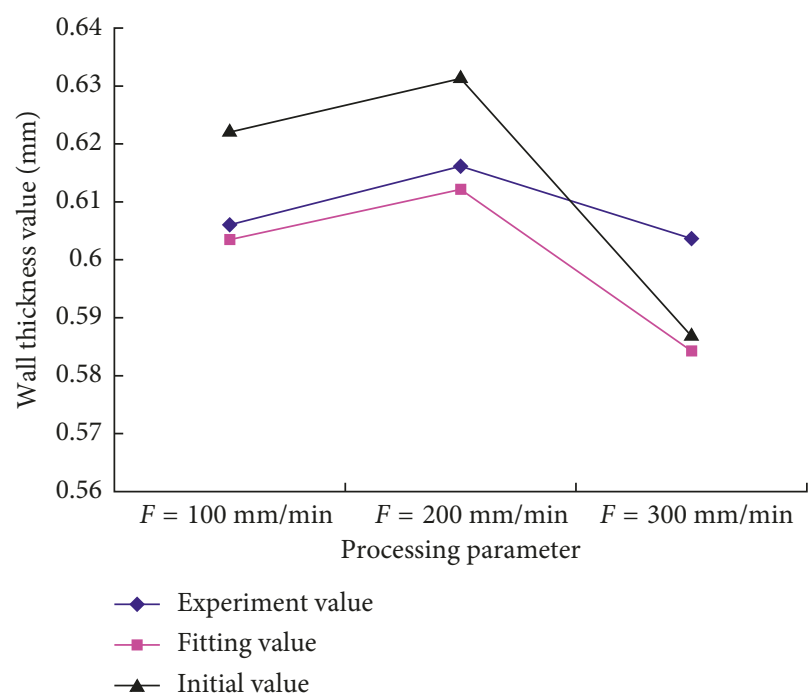

(c)

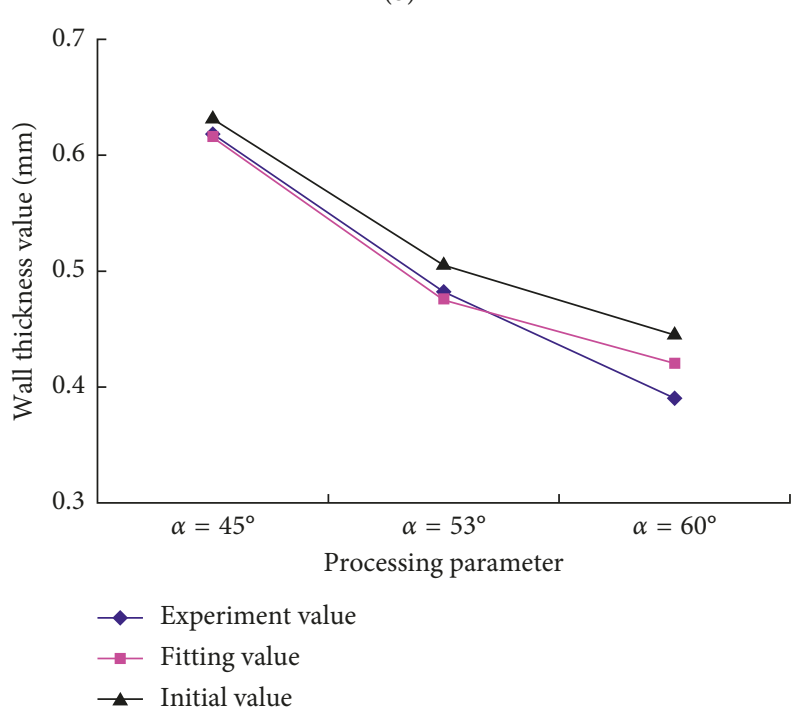

(d)

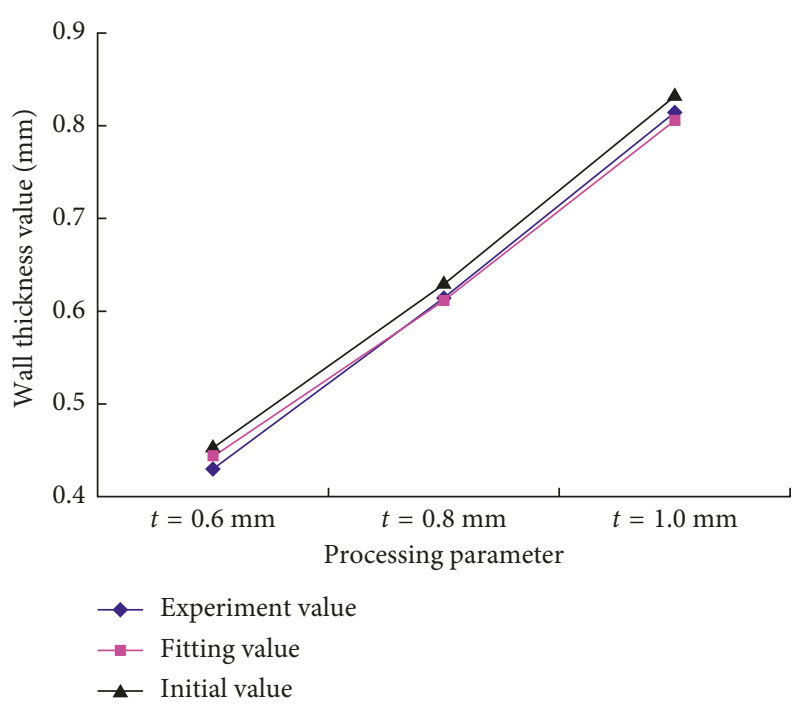

(e)

Figure 10: Comparisons between the theoretical and experimental results. (a) The wall thickness values under different tool diameters, (b) the wall thickness values under different step down values, (c) the wall thickness values under different feed speeds, (d) the wall thickness values under different forming angles, and (e) the wall thickness values under different initial thickness values. 


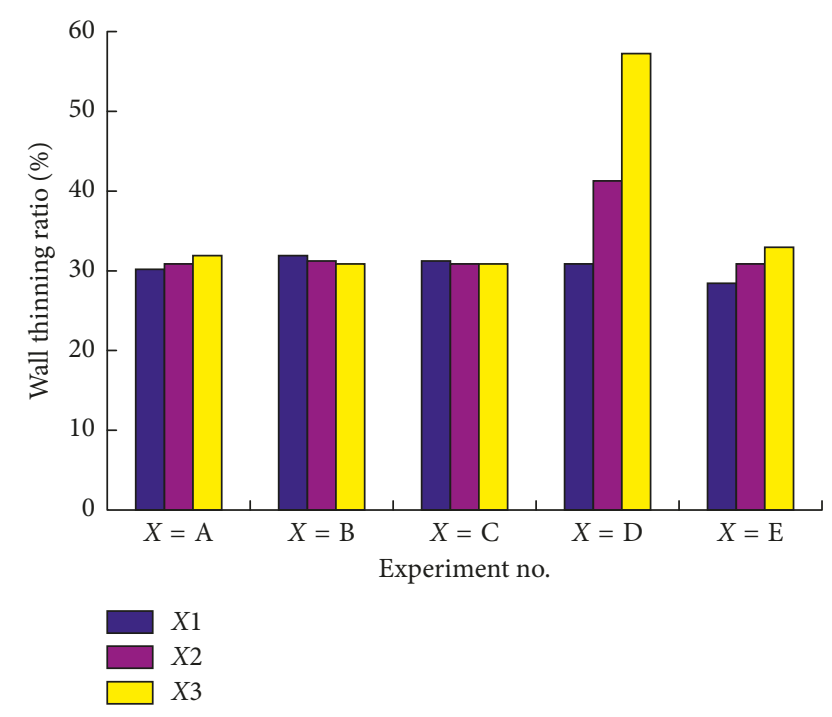

Figure 11: Relationship between the experimental thickness thinning ratio and the process parameters.

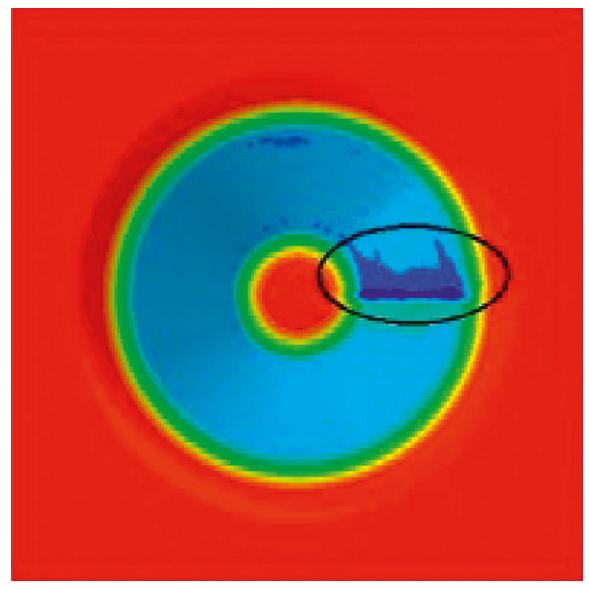

(a)

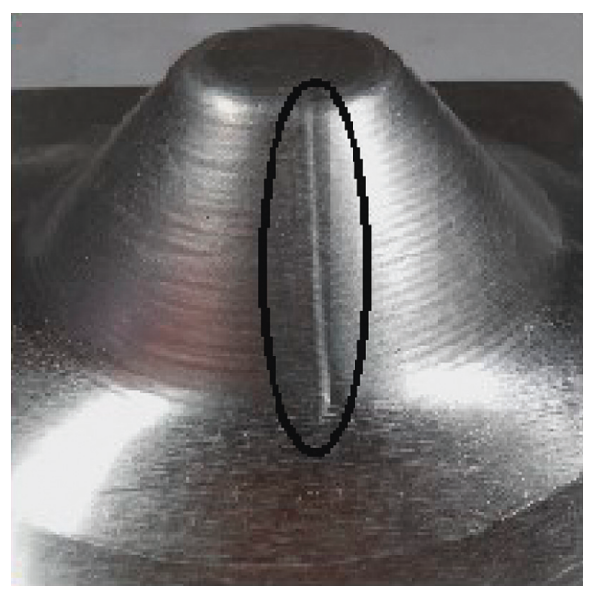

(b)

FIGURE 12: Effect of a single forming trajectory.

alternating inversion trajectory; and the average thickness is $0.7114 \mathrm{~mm}$ and the thinning rate is $28.86 \%$, for the uniformly press point trajectory. From these results, the alternating

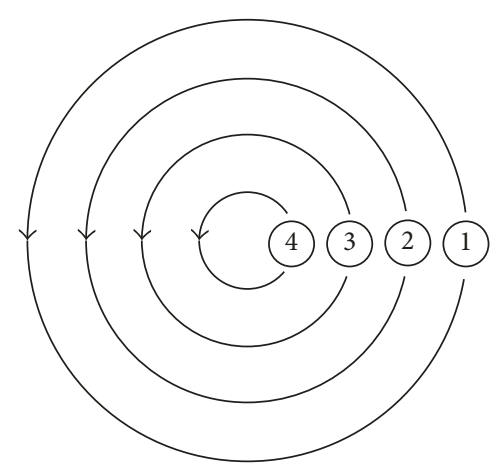

(a)

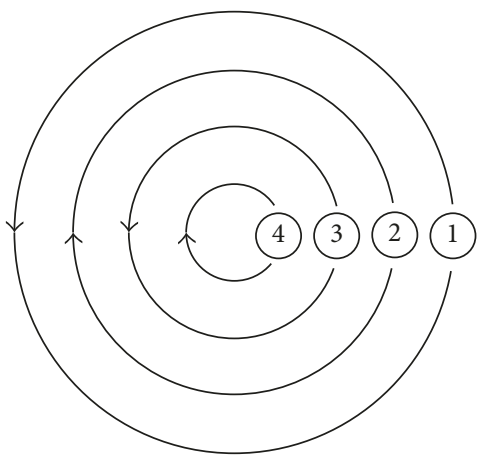

(b)

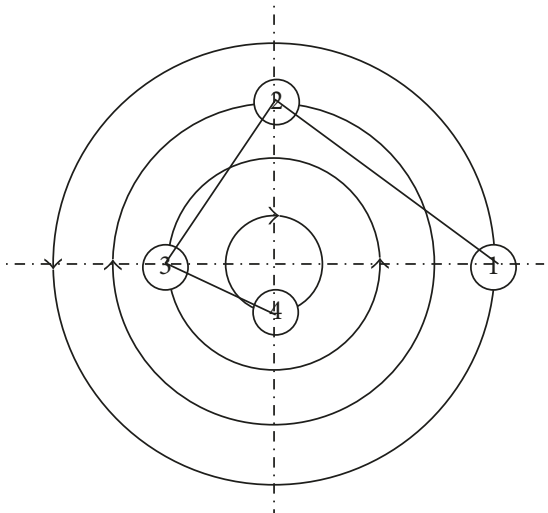

(c)

FIgURE 13: Three different forming trajectories: (a) the single forming trajectory, (b) the alternating inversion trajectory, and (c) the uniform press point trajectory.

inversion trajectory could slightly decrease the thinning rate and the uniformly press point trajectory could obviously decrease the thinning rate; thus, the uniformly press point trajectory can be used to control the sheet-thinning ratio.

\section{Conclusions}

Because the thickness thinning ratio of the deformation zone affects the strength and formability of the forming parts, the influence of different process parameters on the thinning mechanism of the wall thickness and the changing law of the thinning ratio of the forming region was studied and analyzed by using both finite element simulation and experiments. The following conclusions were drawn: 


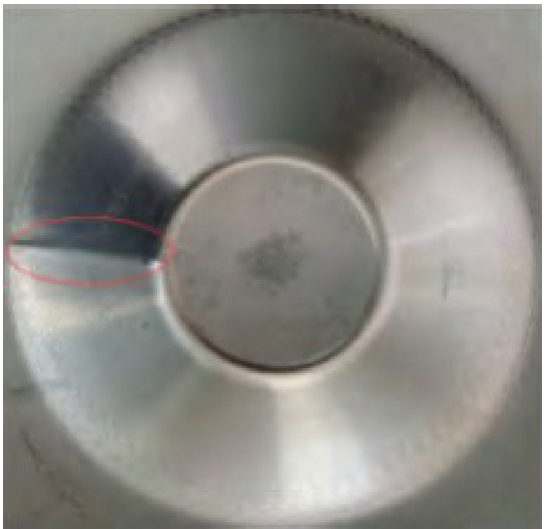

(a)

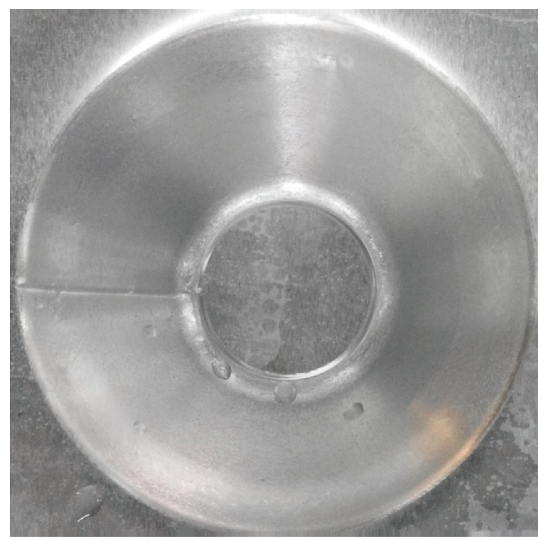

(b)

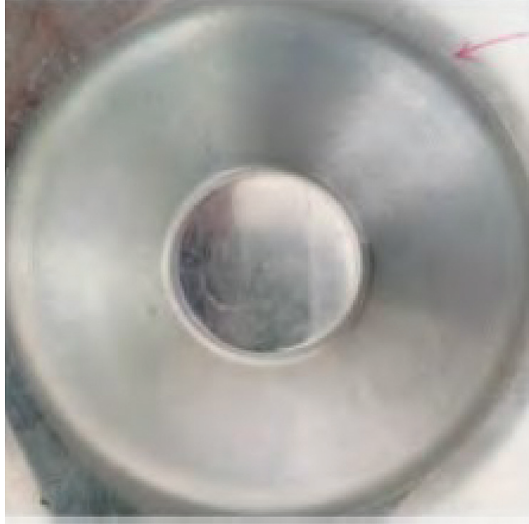

(c)

FIGURE 14: Forming parts of three forming trajectories: (a) single forming trajectory, (b) alternating inversion trajectory, and (c) uniformly press point trajectory.

STH

(avg: 75\%)

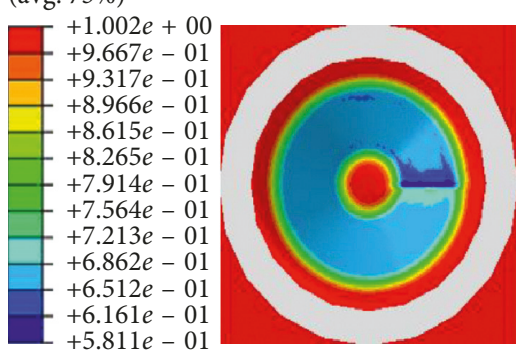

(a)
STH

(avg: 75\%)

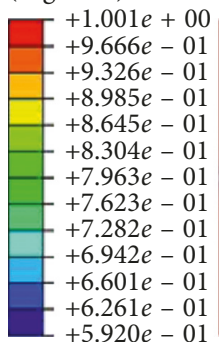

$+5.920 e-0$

STH

(avg: $75 \%)$

(b)

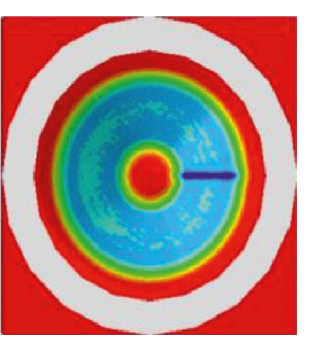

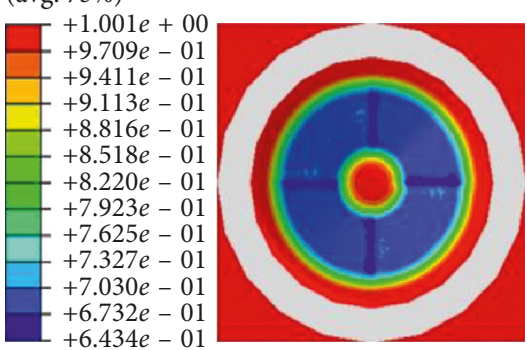

(c)

FIGURE 15: Simulation results of three forming trajectories: (a) single forming trajectory, (b) alternating inversion trajectory, and (c) uniformly press point trajectory.

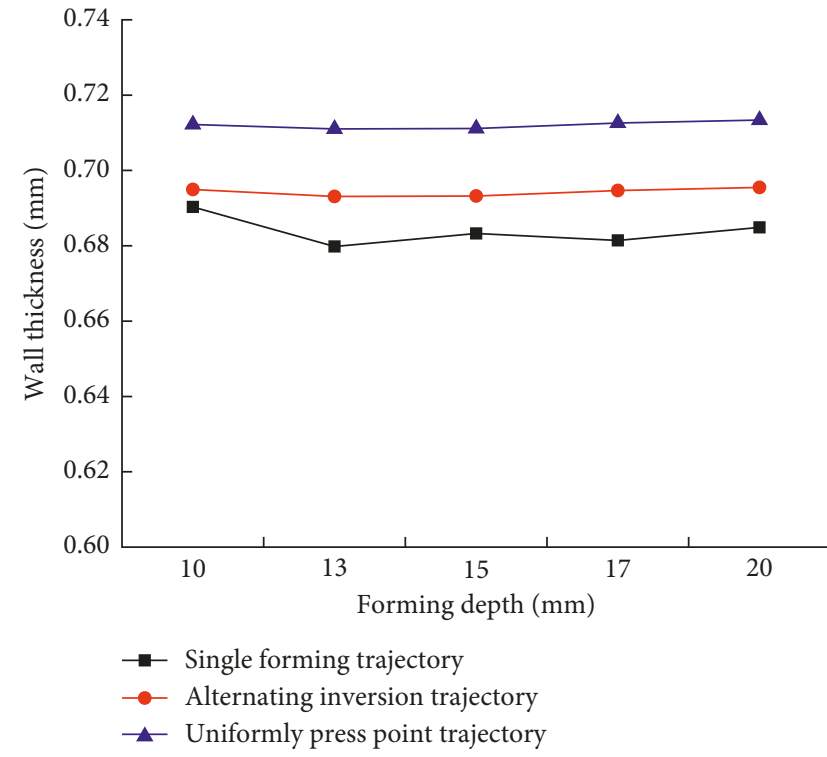

(a)

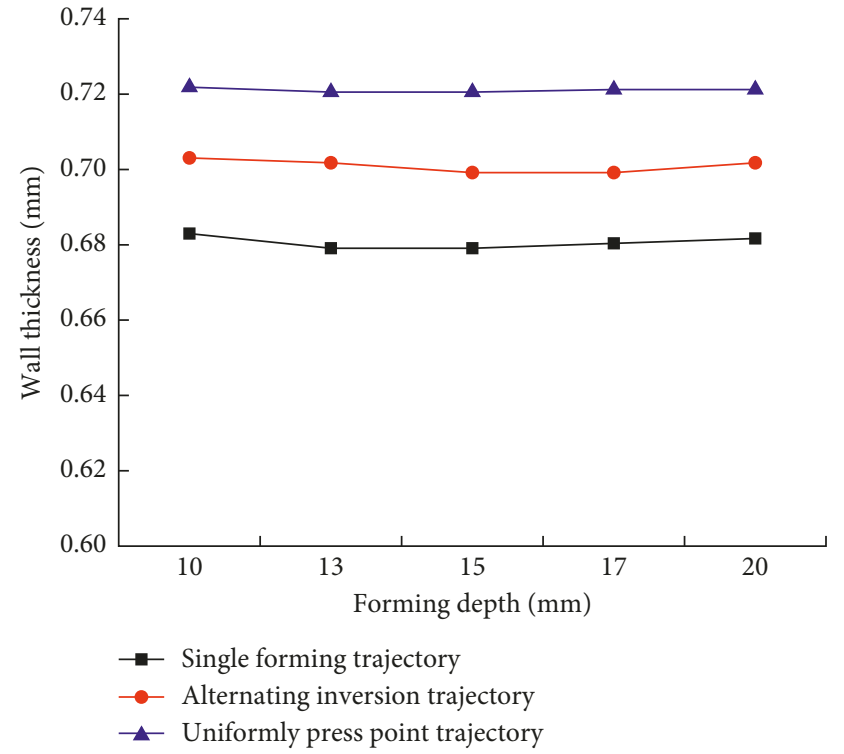

(b)

FIGURE 16: Thickness under three different forming trajectories. (a) Simulation results of the wall thickness and (b) experimental results of the wall thickness. 
(1) Based on the finite element model established and the SPIF process simulated, the average wall thickness values of forming area under different processing parameters were obtained. The high-precision prediction formula of wall thickness obtained was based on the average wall thickness data of the deformation area under different process parameters. The influences of tool head diameter, step down, feed speed, sheet thickness, and forming angle on the change of thinning rate were analyzed, and the laws of change were analyzed and verified by experiments.

(2) In the process of single point incremental forming, the diameter of the tool head has a significant effect on the thinning ratio and the thinning ratio increases with the increase of the diameter of the tool head. The thinning ratio is reduced when the step down increases, but the influence of feed rate on the thinning ratio is notably small. The thinning ratio is increased rapidly when the forming angle increases; thus, the forming angle is the most important factor affecting the thinning ratio. The thinning ratio increases with the thickness of the material, showing that the thickness of the sheet has a significant effect on the thinning ratio of the wall thickness. The uniform press point trajectory was found to reduce the thinning ratio.

(3) In the experiment, the forming parameters were selected with thin sheet material, smaller diameter tool head, smaller step down, larger feed speed, and smaller forming angle to obtain a lower thinning ratio. This method was found to improve the forming limit of sheet and the forming precision.

(4) The three forming trajectories of single forming trajectory, alternating inversion trajectory, and uniformly press point trajectory were analyzed by FEM or experiment; the uniformly press point trajectory was found to make the thickness distribution uniform and to increase the thickness thinning ratio.

(5) The influences of different process parameters on the thinning rate of wall thickness were obtained by both simulation and experimental study of cone parts. No clear mechanism was found from analysis of the data. The formula fitting algorithm is slightly simplistic, and the accuracy is not adequate. Further analysis of the thinning rate mechanism will be conducted, and a more comprehensive and accurate algorithm will be employed to optimize the thickness formulate to better control the wall thinning rate.

\section{Data Availability}

The data used to support the findings of this study are available from the corresponding author upon request.

\section{Conflicts of Interest}

The authors declare that they have no conflicts of interest.

\section{Acknowledgments}

The authors would like to acknowledge the National Natural Science Foundation of China (51475366 and 51475146), the Science and Technology Planning Project of Shaanxi Province (Grant no. 2016JM5074), and the Key Laboratory of Scientific Research Projects of Shaan'xi Educational Committee (Grant no. 12JS072).

\section{References}

[1] S. B. M. Echrif and M. Hrairi, "Research and progress in incremental sheet forming processes," Materials and Manufacturing Processing, vol. 26, no. 11, pp. 1404-1414, 2011.

[2] V. C. Do, D. T. Nguyen, J. H. Cho, and Y. S. Kim, "Incremental forming of 3D structured aluminum sheet," International Journal of Precision Engineering and Manufacturing, vol. 17, no. 2, pp. 217-223, 2016.

[3] J. Jeswiet, F. Micari, G. Hirt et al., "Asymmetric single point incremental forming of sheet metal," CIRP Annals-Manufacturing Technology, vol. 54, no. 2, pp. 88-114, 2005.

[4] K. R. Jackson, J. M. Allwood, and M. Landert, "Incremental forming of sandwich panels," Journal of Materials Processing Technology, vol. 204, no. 1-3, pp. 290-303, 2008.

[5] R. Bahloul, H. Arfa, and H. Belhadjsalah, "A study on optimal design of process parameters in single point incremental forming of sheet metal by combining Box-Behnken design of experiments, response surface methods and genetic algorithms," International Journal of Advanced Manufacturing technology, vol. 74, no. 1-4, pp. 163-185, 2014.

[6] G. Hussain, K. A. Al-Ghamdi, H. Khalatbari et al., "Forming parameters and forming defects in incremental forming process," Materials and Manufacturing Processes, vol. 29, no. 4, pp. 454-460, 2014.

[7] Z. Yao, Y. Li, M. Yang, Q. Yuan, and P. Shi, "Parameter optimization for deformation energy and forming quality in single point incremental forming process using response surface methodology," Advances in Mechanical Engineering, vol. 9, no. 7, pp. 1-15, 2017.

[8] J.-C. Li, C. Li, and T.-G. Zhou, "Thickness distribution and mechanical property of sheet metal incremental forming based on numerical simulation," Transactions of Nonferrous Metals Society of China, vol. 22, no. 1, pp. s58-s64, 2012.

[9] T. McAnulty, J. Jeswiet, and M. Doolan, "Formability in single point incremental forming: a comparative analysis of the state of the art," CIRP Journal of Manufacturing Science and Technology, vol. 16, pp. 43-54, 2017.

[10] R. Malhotra, L. Xue, T. Belytschko, and J. Cao, "Mechanics of fracture in single point incremental forming," Journal of Materials Processing Technology, vol. 212, no. 7, pp. 15731590, 2012.

[11] G. Hussain, L. Gao, and N. U. Dar, “An experimental study on some formability evaluation methods in negative incremental forming," Journal of Materials Processing Technology, vol. 186, no. 1-3, pp. 45-53, 2007.

[12] K. Jackson and J. Allwood, "The mechanics of incremental sheet forming," Journal of Materials Processing Technology, vol. 209, no. 3, pp. 1158-1174, 2008.

[13] Y. H. Kim and J. J. Park, "Effect of process parameters on formability in incremental forming of sheet metal," Journal of Materials Processing Technology, vol. 130-131, pp. 42-46, 2002.

[14] C. Bouffioux, C. Lequesne, H. Vanhove et al., "Experimental and numerical study of an AlMgSc sheet formed by an 
incremental process," Journal of Materials Processing Technology, vol. 211, no. 11, pp. 1684-1693, 2011.

[15] M. B. Silva, P. S. Nielsen, N. Bay, and P. A. F. Martins, "Failure mechanisms in single-point incremental forming of metals," International Journal of Advanced Manufacturing Technology, vol. 56, no. 9-12, pp. 893-903, 2011.

[16] D. Young and J. Jeswiet, "Wall thickness variations in singlepoint incremental forming," Proceedings of the Institution of Mechanical Engineers, vol. 218, no. 11, pp. 1453-1459, 2004.

[17] G. Hirt, S. Junk, M. Bambach et al., "Process limits and material behaviour in incremental sheet forming with CNCtools," Materials Science Forum, vol. 426-432, pp. 3825-3830, 2003.

[18] K. A. Al-Ghamdi and G. Hussain, "Threshold tool-radius condition maximizing the formability in SPIF considering a variety of materials: experimental and Fe investigations," International Journal of Machine Tools and Manufacture, vol. 88, pp. 82-94, 2014.

[19] P. Martins, N. Bay, M. Skjoedt et al., "Theory of single point incremental forming," CIRP Annals-Manufacturing Technology, vol. 57, no. 1, pp. 247-252, 2008.

[20] L. Zhou, "Research on the thickness change laws in numerical control incremental sheet forming," Journal of Mechanical Engineering, vol. 47, no. 18, pp. 50-54, 2011.

[21] S. Xiao and J.-Z. Gao, "Research on critical forming angle of uniform thickness in single-path incremental forming for conical part," Forging \& Stamping Technology, vol. 1, no. 37, pp. 49-54, 2012.

[22] J. Li, "Experimental and numerical research on thickness variation dieless sheet mental incremental forming," Hot Working Technology, vol. 7, no. 40, pp. 1-4, 2011.

[23] C. Yu and J. Gao, "Numerical simulation for thickness thinning of deformation zone on hole-flanging by incremental forming," Forging \& Stamping Technology, vol. 2, no. 40 , pp. $53-59,2015$.

[24] H.-Z. Cao and J.-Z. Gao, "Research on influencing factors of region with stable thickness of conical part in incremental forming process," Forging \& Stamping Technology, vol. 6, no. 37, pp. 17-23, 2012.

[25] H.-Y. Wei and L. Gao, "Investigation of thickness distribution of incrementally formed sheet mental parts," Journal of Shandong University, vol. 6, no. 39, pp. 82-87, 2009.

[26] W. Zhao and Y. Zhan, "Study on law of incremental forming square cone-shaped parts based on numerical simulation," Hot Working Technology, vol. 1, no. 42, pp. 103-105, 2013.

[27] I. Bagudanch, M. L. Garcia-Romeu, G. Centeno, A. Elías-Zúñiga, and J. Ciurana, "Forming force and temperature effects on single point incremental forming of polyvinylchloride," Journal of Materials Processing Technology, vol. 219, pp. 221-229, 2015.

[28] I. Bagudanch, M. Vivesmestres, M. Sabater et al., "Polymer incremental sheet forming process: temperature analysis using response surface methodology," Materials \& Manufacturing Processes, vol. 32, no. 1, pp. 44-53, 2016.

[29] L. Filice, G. Ambrogio, and M. Gaudioso, "Optimised toolpath design to reduce thinning in incremental sheet forming process," International journal of Material Forming, vol. 6, no. 1, pp. 173-178, 2013. 


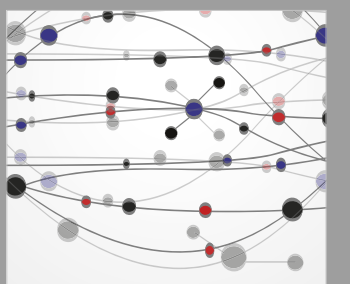

The Scientific World Journal
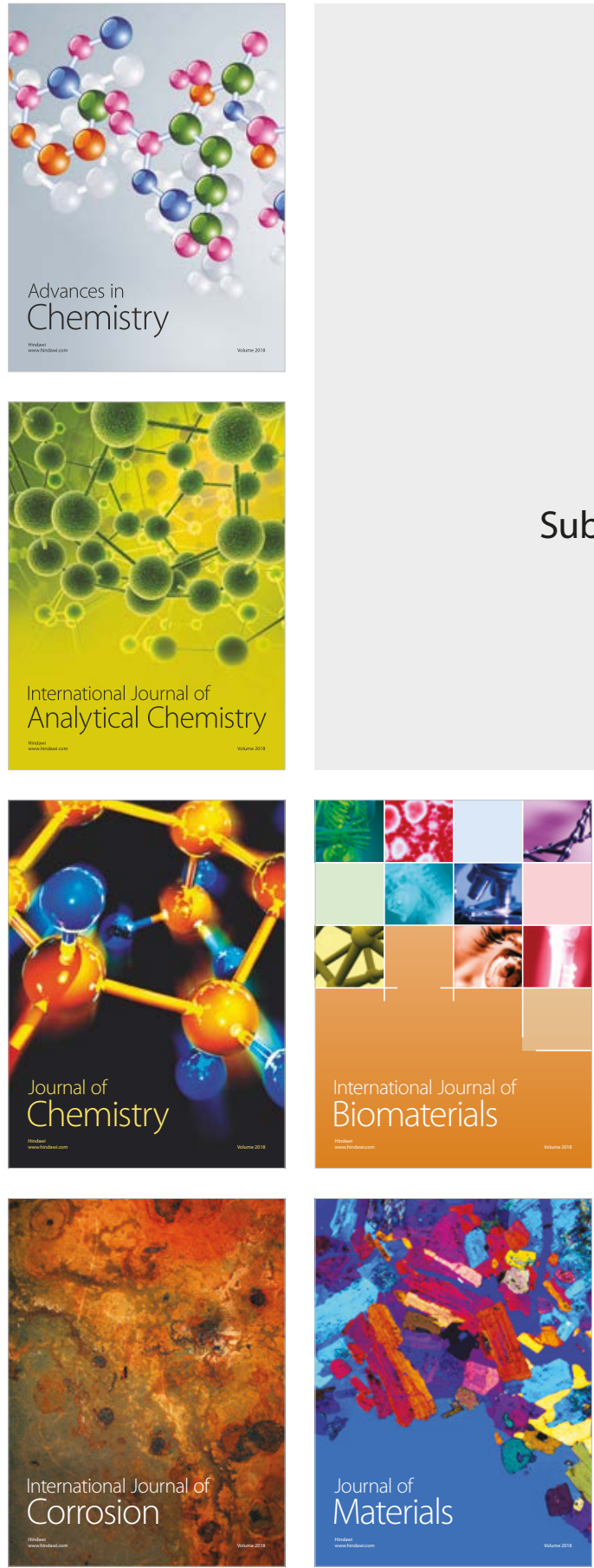

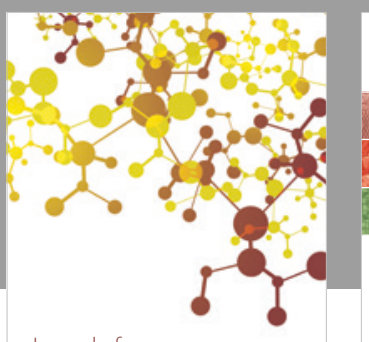

Journal of

Applied Chemistry
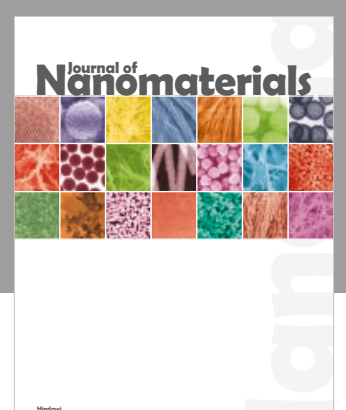

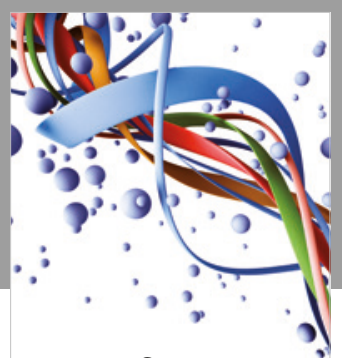

Scientifica

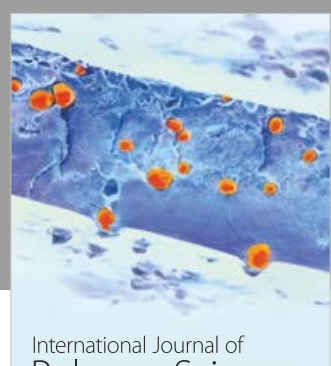

Polymer Science

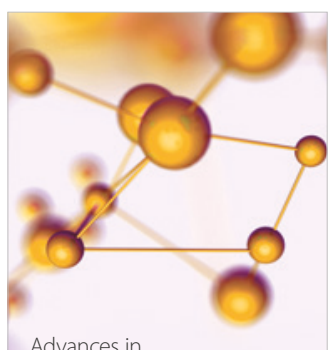

Physical Chemistry
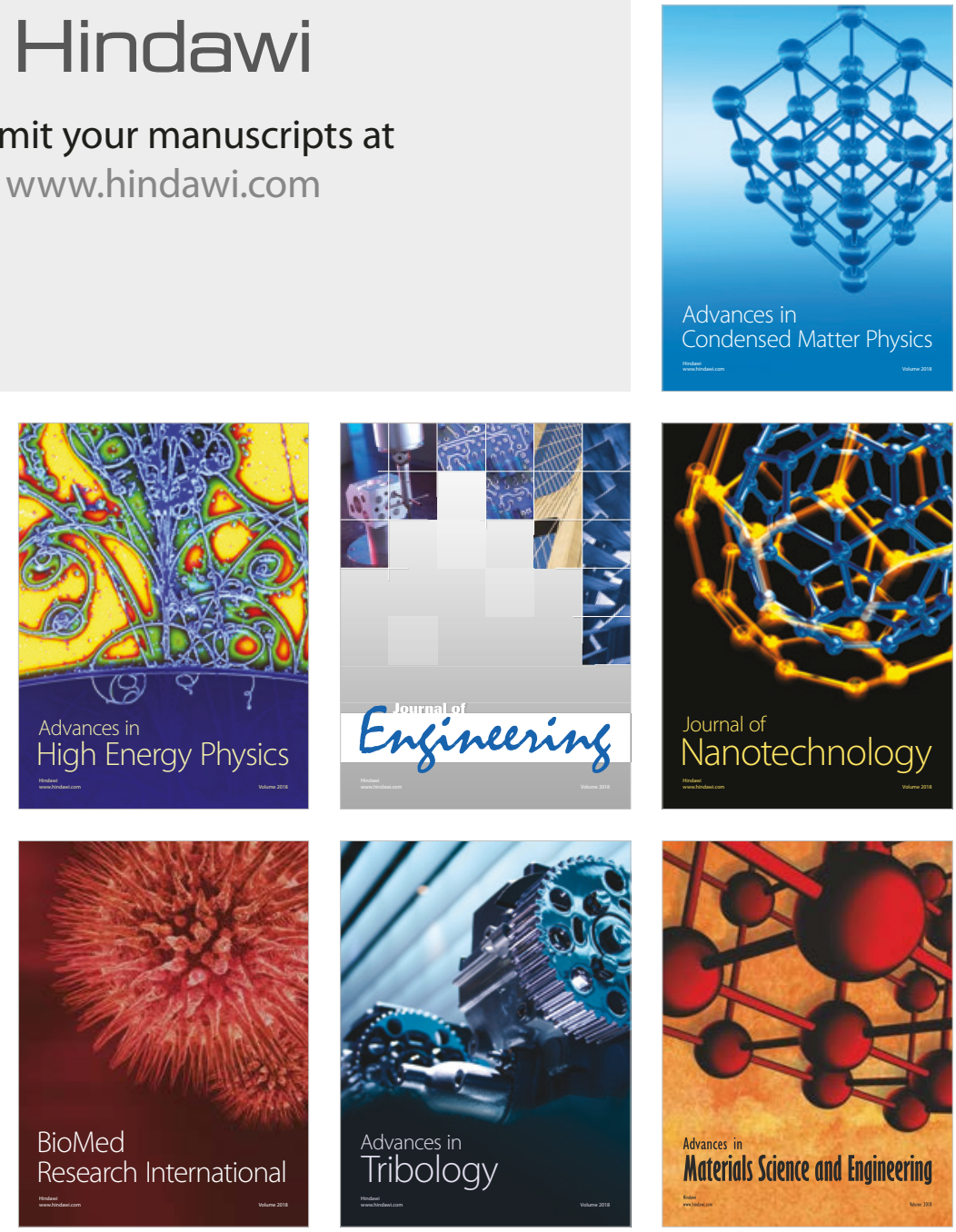